\title{
Behavioural responses of western gray whales to a 4-D seismic survey off northeastern Sakhalin Island, Russia
}

\author{
Glenn Gailey ${ }^{1, *}$, Olga Sychenko', Trent McDonald ${ }^{2}$, Roberto Racca ${ }^{3}$, \\ Alexander Rutenko ${ }^{4}$, Koen Bröker ${ }^{5,6}$ \\ ${ }^{1}$ Texas A\&M University, 200 Seawolf Pkwy, Galveston, TX 77553, USA \\ ${ }^{2}$ West, Inc. Western EcoSystems Technology, 200 S. Second St., Laramie, WY 82070, USA \\ ${ }^{3}$ JASCO Applied Sciences (Canada) Ltd., 2305-4464 Markham Street, Victoria, BC V8Z 7X8, Canada \\ ${ }^{4}$ V.I. Il'ichev Pacific Oceanological Institute FEB RAS, ul. Baltiiskaya 43, Vladivostok 690041, Russia \\ ${ }^{5}$ Shell Global Solutions, Lange Kleiweg 40, 2288GK Rijswijk, The Netherlands \\ ${ }^{6}$ Marine Evolution and Conservation, Groningen Institute for Evolutionary Life Sciences, University of Groningen, \\ Nijenborgh 7, 9747AG Groningen, The Netherlands
}

\begin{abstract}
A seismic survey was conducted off the northeastern coast of Sakhalin Island, Russia in 2010. The survey area was adjacent to the only known near-shore feeding ground of the Critically Endangered population of western gray whales Eschrichtius robustus in the western Pacific south of the Aleutian Islands. This study examined the effectiveness of efforts to minimize the behavioural responses of the whales to vessel proximity and sound during the survey. Two shore-based behavioural observation teams monitored whale movements and respirations pre-, during and post-seismic survey. Theodolite tracking and focal-animal follow methods were used to collect behavioural data. Mixed linear models were used to examine deviations from 'normal' patterns in 10 movement and 7 respiration response variables in relation to vessel proximity, vessel/ whale relative orientations and 8 received sound metrics to examine if seismic survey sound and/or vessel activity influenced the whales' behaviour. Behavioural state and water depth were the best 'natural' predictors of whale movements and respiration. After considering natural variation, none of the response variables were significantly associated with seismic survey or vessel sounds. A whale's distance from shore and its orientation relative to the closest vessel were found to be significantly influenced by vessel proximity, which suggested some non-sound related disturbance. The lack of evidence that the whales responded to seismic survey sound and vessel traffic by changing either their movement or respiration patterns could indicate that the current mitigation strategy is effective. However, power analyses suggest that our sample sizes were too small to detect subtle to moderate changes in gray whale behaviour.
\end{abstract}

KEY WORDS: Western gray whale $\cdot$ Behaviour $\cdot$ Seismic survey $\cdot$ Anthropogenic disturbance Movement $\cdot$ Respiration

\section{INTRODUCTION}

Since international protection of gray whales Eschrichtius robustus from commercial whaling was put in place in 1946, the eastern North Pacific population has made a strong recovery to around 20000

${ }^{*}$ Corresponding author: ggailey@cascadiaresearch.org individuals (Rugh et al. 2005, Jones \& Swartz 2009, Laake et al. 2012) with an estimated annual growth rate of $\sim 3.2 \%$ (Punt \& Wade 2012). This post-commercial whaling recovery is regarded as a conservation success. However, unlike the eastern population, the population in the western North Pacific has not

() The authors 2016. Open Access under Creative Commons by Attribution Licence. Use, distribution and reproduction are unrestricted. Authors and original publication must be credited. Publisher: Inter-Research · www.int-res.com 
recovered and remains a small remnant of what it was in the $19^{\text {th }}$ century. Around 140 (CI: 134-146) non-calf individuals regularly occur off Sakhalin Island, Russia, with 36 reproductive females and an annual population rate of increase of $3.3 \%$ (Cooke et al. 2013), although issues regarding population structure remain (see IWC 2015). The western gray whale population is considered to be one of the most endangered baleen whale populations (Clapham \& Baker 2002, Weller et al. 2002) and is currently listed as Critically Endangered by IUCN and Category I in the Red Book of Russia (Red Book of the Russian Federation 2000, Baillie et al. 2004).

Human activities, particularly those related to oil and gas exploration and development, have been increasing in the past 15 yr off northeastern Sakhalin Island, on and near the only known major feeding area of this population of gray whales. To minimize the impacts of such activity on the whales, several mitigation and monitoring plans (MMP) have been implemented targeting specific activities, such as seismic surveys, platform installation, dredging and pipeline placement (Johnson et al. 2007, SEIC 2005, 2006, 2007). Despite efforts to reduce overall sound exposure levels, responses by the whales were observed, including changes in distribution and behaviour (Weller et al. 2002, 2005, Gailey et al. 2007a,b, 2010, Yazvenko 2007a,b). However, it is uncertain whether such localized displacements or changes in behaviour have had population-level consequences.

In 2010, Sakhalin Energy Investment Company (Sakhalin Energy) conducted a geophysical seismic survey of the Astokh oil and gas field. Constrained by weather, safety concerns and ice coverage, the timing of the seismic survey - between mid-June and early July - overlapped with the gray whales' summer feeding period (June to November). Prior to the start of the seismic survey, Sakhalin Energy and the IUCN Western Gray Whale Advisory Panel (WGWAP), primarily through its Seismic Survey Task Force (SSTF), collaborated to develop an MMP to minimize the impacts of the survey on the whales (SSTF 2007-2011, Nowacek et al. 2013, Bröker et al. 2015). The primary mitigation measure was to conduct the seismic survey as early in the season as feasible to avoid temporal overlap with the presence of whales during their foraging season. This strategy was dependent on sea ice coverage in the region, which is typically ice-free from late May to mid-June. In addition to minimizing possible disruptions to gray whale feeding activities, the early scheduling of seismic survey activity was intended to reduce the exposure to its sound of recent gray whale mothers arriv- ing with their dependent calves. Mother-calf pairs are the last whales to arrive on the feeding grounds and are presumably among the more sensitive individuals to anthropogenic activity (Jones \& Swartz 2009).

Other mitigation measures were adopted to minimize exposure to sound levels above $163 \mathrm{~dB}$ re $1 \mu \mathrm{Pa}$ RMS. This exposure threshold was based on playback experiments conducted with gray whales on feeding grounds in the Bering Sea, in which $~ 10 \%$ of the whales stopped feeding and moved away from transient sounds (seismic survey pulses) when received levels exceeded $163 \mathrm{~dB}$ re $1 \mu \mathrm{Pa}$ RMS (Malme et al. 1986, 1988). In a 2001 seismic survey off Sakhalin that was conducted later in the feeding season when more animals were present (August and September), mitigation measures had been implemented using similar criteria to limit exposure of feeding gray whales, and yet significant behavioural, abundance and distribution responses were still observed (Weller et al. 2002, 2005, Gailey et al. 2007a, Yazvenko et al. 2007a,b). It remains unclear whether the whales were responding to the sound levels to which they were exposed or to some combination of this and other factors related to the seismic survey activity. Studies of migrating gray whales have demonstrated that they react to the direction of the sound source as opposed to overall sound levels. For example, Tyack \& Clark (1998) found that migrating gray whales avoided a low-frequency acoustic sound source when it was located directly in their alongshore path, but exhibited little or no reaction to an offshore sound source at similar received levels.

The objective of this study was to evaluate the effectiveness of the mitigation measures implemented in the 2010 seismic survey by testing for changes in whale movements and respirations in response to the proximities, orientations and sounds of vessels as well as to the seismic survey pulses. The null hypothesis was that whale behaviour was not affected by continuous and/or pulse sounds and/or proximity of vessels during the seismic survey. A number of behavioural studies of baleen whale responses to potential anthropogenic disturbance have found that response is highly dependent on the context of the exposure, e.g. factors such as season or an animal's behavioural state and reproductive status (Beale \& Monaghan 2004, Beale 2007, Nowacek et al. 2007, Southall et al. 2007, Ellison et al. 2012, Dunlop et al. 2013, Robertson et al. 2013). Therefore, both 'natural' (e.g. spatial, temporal, environmental, behavioural) and anthropogenic (sound and non-sound related) factors were considered in this study. 


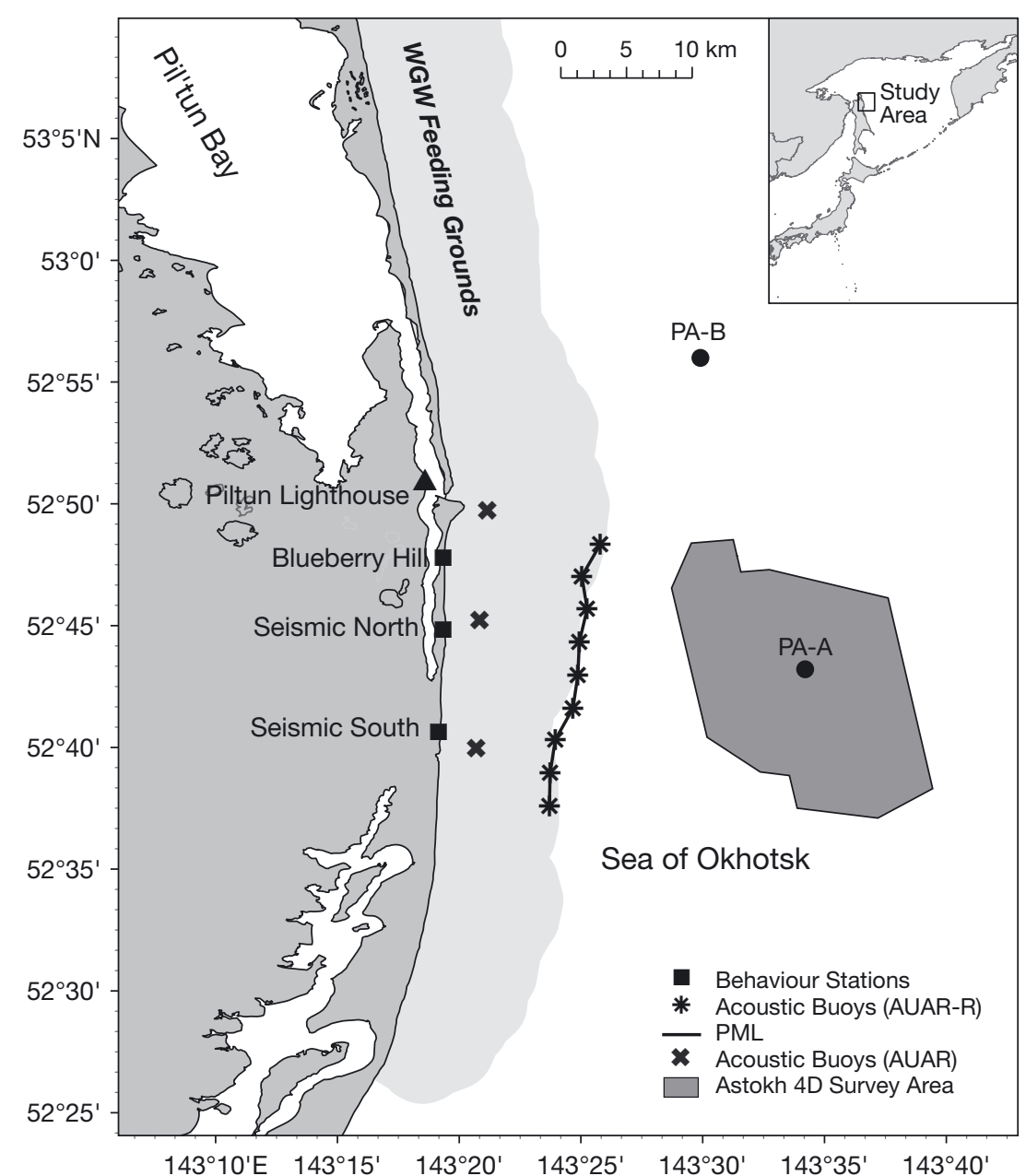

Fig. 1. Study area, acoustic buoys with (AUAR-R) and without (AUAR) a radiotelemetric channel $* / \mathbf{*}$, respectively), perimeter monitoring line (PML: indicating the offshore boundary of the near-shore feeding area; black line) and the 3 shore-based observation platforms (black squares) used to monitor western gray whale (WGW) Eschrichtius robustus behaviour during the seismic survey in 2010. PA-A and PA-B: the 2 existing oil platforms in the study area; dark gray shading: area of the seismic survey. See Bröker et al. (2015) for further details

\section{MATERIALS AND METHODS}

\section{Study area}

The seismic survey was conducted close to a nearshore summer feeding ground of a gray whale population off northeastern Sakhalin Island, Russia (Fig. 1). This area is characterized by a sandy substrate with a gradually sloping continental slope (Fadeev 2010). During the seismic survey, whale distribution, numbers, behaviour, respirations and movements were monitored by 2 shore-based behavioural teams. For behavioural monitoring, on every good-weather day (good visibility with Beaufort < 4) the 2 teams collected data at 2 of 3 shore stations on the southern spit in the mouth (entrance) of Piltun Bay (Fig. 1). The 'Seismic North' station was consistently used as an observation platform throughout the study period. The 'Seismic South' station was used in the earlier part of the field season; an additional station, 'Blueberry Hill', was introduced later in the field season because more whales were observed in this area compared to the 'Seismic South' station. The shorebased behavioural platforms offered relatively low ( 7.8 to $9.7 \mathrm{~m}$ ) elevations for observations but were sufficiently high to monitor the near-shore feeding ground, which extended less than $15 \mathrm{~km}$ from shore.

\section{Movement patterns of gray whales}

Gray whale movements were recorded using theodolite tracking methodology (Würsig et al. 1991, 2002, Gailey \& Ortega-Ortiz 2002). We used Sokkia DT5A digital theodolites that had a 30-power monocular magnification and a $5 \mathrm{~s}$ level of precision. Gray whales were tracked to a maximum of $5 \mathrm{~km}$ from the shore station, with adjacent stations coordinating to track the same individual moving between stations. Given the relatively low station elevations, observations greater than $5 \mathrm{~km}$ introduced more distance estimation errors that added more variability in movement parameters. Whales were tracked continuously until the animal was either no longer visible or environmental conditions prevented further tracking. Single or recognizable individuals (such as highly distinctive animals or mothers with calves) were tracked preferentially to avoid measurement errors from tracking different individuals within a group. If a single or recognizable animal was unavailable, groups as a whole were tracked to record general movement patterns. However, data from group tracking were not included in this paper. Including mother-calf pairs, the majority of groups $(\sim 75 \%)$ typically seen on the Sakhalin near-shore feeding area are single individuals (Gailey et al. 2010). The geographic locations of the animals were estimated in real time and displayed in a 
GIS system that illustrated their positions relative to current seismic survey activity, the perimeter monitoring line (see Fig. 1) and the $163 \mathrm{~dB}$ re $1 \mu \mathrm{Pa}$ RMS mitigation A-zone boundary for the given seismic acquisition line (Bröker et al. 2015). A theodolite software system, 'Pythagoras', was used to calculate geographic positions and plot GIS displays in real time (Gailey \& Ortega-Ortiz 2002).

\section{Focal-animal behavioural observations}

Behavioural and respiration patterns were recorded using focal-animal observational techniques (Altmann 1974, Martin \& Bateson 1993). A focal-animal behaviour session was initiated when observers identified a single whale or recognizable animal (i.e. the focal-animal) that could be monitored reliably enough so that respiration and critical behavioural events would not be missed. A focal-animal session was terminated once the whale moved out of the study area or environmental conditions fell below acceptable limits (visibility $<5 \mathrm{~km}$, wind $>4$ Beaufort or gust speeds $>20 \mathrm{~km} \mathrm{~h}^{-1}$ ). At least $1 \mathrm{ob}-$ server visually followed individuals with the aid of $7 \times 50$ hand-held Fujinon FMTRC-SX binoculars. The behavioural observer verbally stated each behavioural event, which was recorded by a computer operator using a programmable keyboard connected to the Pythagoras software (Gailey \& Ortega-Ortiz 2002). Focal-animal sessions occurred in conjunction with theodolite tracking of the same focal-animal, which provided the ability to link spatial details (i.e. geographic location, depth, etc.) to focal follow observations.

\section{Data processing and response variables}

Prior to computing response variables, all movement data were re-sampled on a $90 \mathrm{~s}$ period to avoid issues of under- or over-sampling and to standardize step lengths of movement (Turchin 1998, Gailey et al. $2007 b, 2010)$. The 90 s re-sampling interval was chosen based on an autocorrelation analysis of the movement data, which indicated that correlation initially died out at around $90 \mathrm{~s}$ on average (Würsig et al. 2002). After re-sampling, behavioural response variables were calculated for every 10.5 min interval (hereafter referred to as a 'bin') of continuous observation. This time interval was chosen to end with a re-sampled point. In other words, a total of 7 re-sampled spatial points were represented in each bin. We chose bins of $10.5 \mathrm{~min}$ in length as a compromise between allowing adequate time to acquire data upon which responses could be measured and the need to assess short-term behavioural responses. Similar bin lengths have been used in previous studies examining anthropogenic impacts on gray whales and have proved adequate to obtain meaningful results (Gailey et al. 2007a,b, 2010). Bins that did not yield adequate data for the entire 10.5 min duration (i.e. the last bin in a sequence for a given trackline) were removed from the dataset. For each of these bins, 10 movement and 7 respiration variables were derived from theodolite tracking and focal-animal follow observations (Table 1). Collectively, we termed these 17 variables the 'response variables'.

The behavioural state of the whales in each bin was classified as feeding, feeding/travelling, travelling or mixed, based on field observations regarding a whale's (or whales') predominant state at the time. Feeding behaviour was characterized by non-directional movement where whale(s) generally remained in the same area with frequent periods of diving. Travelling behaviour was characterized as swimming in one general direction, often with consistent surfacerespiration-dive patterns. Feeding/travelling behaviour consisted of whale(s) swimming at relatively low speeds with frequent periods of diving and with directional persistence in movement. Mixed behaviour denoted any combination of unknown, transitional, or unrecognized behaviour comprising a substantial portion of the bin.

\section{Acoustic monitoring and sound-level estimation}

Vessel and seismic survey sounds were recorded with 12 Autonomous Underwater Acoustic Recorders (AUARs) with a range of 2 to $15000 \mathrm{~Hz}$ (Borisov et al. 2008). Nine of these AUARs (denoted as AUARRs) were equipped with a digital radiotelemetric channel that provided real time acoustic data within the range of 2 to $2000 \mathrm{~Hz}$ with a potential dynamic range of $96 \mathrm{~dB}$ (Kovzel \& Rutenko 2009). The AUAR-Rs were equally spaced along a $20 \mathrm{~km}$ segment of the offshore boundary of the gray whale feeding area (Fig. 1) and provided real time data to a shore-based acoustic team. Three non-telemetric AUARs were located closer to shore in water depths of $10 \mathrm{~m}$ to provide detailed information on sound propagation for post hoc analyses (Rutenko et al. 2012). Racca et al. (2015, this Theme Section) provide further details of acoustic data acquisition during the seismic survey. 
Table 1. Response variables derived from behavioural observations of the movements and respiration of western gray whales Eschrichtius robustus

\begin{tabular}{|c|c|}
\hline Variable & Definition \\
\hline \multicolumn{2}{|l|}{ Movement } \\
\hline Speed (Spd) & $\begin{array}{l}\text { Distance travelled between } 2 \text { sequential fixed points within a trackline divided by the } \\
\text { time interval between the } 2 \text { points. A mean speed value was taken for each bin }\end{array}$ \\
\hline Acceleration (Acc) & $\begin{array}{l}\text { Changes within leg speed to determine if an animal is generally increasing or } \\
\text { decreasing speeds within a trackline. A mean acceleration was taken for each bin }\end{array}$ \\
\hline Linearity (Lin) & $\begin{array}{l}\text { An index of deviation from a straight line, calculated by dividing the net geographic } \\
\text { distance between the first and last fix of a bin divided by the cumulative distances } \\
\text { within a bin }\end{array}$ \\
\hline Mean vector length (Trk_R) & $\begin{array}{l}\text { A directionality index } r \text { (Cain 1989) dependent on angular changes: range from } 0 \\
\text { (great scatter) to } 1 \text { (all movements in the same direction) }\end{array}$ \\
\hline Reorientation rate $(\mathrm{RR})$ & $\begin{array}{l}\text { Magnitude of bearing changes, calculated by the summation of absolute values of all } \\
\text { bearing changes within a bin divided by the entire duration of the bin }\end{array}$ \\
\hline Direction of movement (mDir) & $\begin{array}{l}\text { A mean geographic bearing of the general movement for the bin. Sine(direction) } \\
\text { was an indicator of whale movement inshore-offshore and cosine(direction) } \\
\text { indicated whale movement alongshore }\end{array}$ \\
\hline Distance-from-shore (distshore) & $\begin{array}{l}\text { Mean distance of animal from the closest perpendicular location from the nearby } \\
\text { coastline }\end{array}$ \\
\hline $\begin{array}{l}\text { Relative orientation of whale } \\
\text { to closest vessel (ROW_CV) }\end{array}$ & $\begin{array}{l}\text { Orientation }\left(0-180^{\circ}\right) \text { of a whale relative to the directional persistence in movement of } \\
\text { the closest vessel of approach }\end{array}$ \\
\hline $\begin{array}{l}\text { Relative orientation of whale } \\
\text { to seismic vessel (ROW_SV) }\end{array}$ & $\begin{array}{l}\text { Orientation }\left(0-180^{\circ}\right) \text { of a whale in relation to the directional persistence in movement } \\
\text { of the seismic vessel }\end{array}$ \\
\hline Ranging index (range) & $\begin{array}{l}\text { Measure of the minimal diagonal area of the whale's track incorporating its course } \\
\text { and track duration (Jahoda et al. 2003) }\end{array}$ \\
\hline \multicolumn{2}{|l|}{ Respiration } \\
\hline Respiration interval (RI) & $\begin{array}{l}\text { Duration less than } 60 \mathrm{~s} \text { between subsequent exhalations per surfacing. Mean } \\
\text { respiration intervals were calculated for each bin }\end{array}$ \\
\hline Dive time & $\begin{array}{l}\text { Any interval where exhalation period is greater than } 60 \mathrm{~s} \text {. Mean dive times were used } \\
\text { for each bin }\end{array}$ \\
\hline Surface time & Mean duration the animal remains at or near the surface within a bin \\
\hline $\begin{array}{l}\text { Number blows/surfacing } \\
\text { (NumSurfs) }\end{array}$ & Mean number of exhalations per surfacing for each bin \\
\hline Time at surface & Mean percent of time animal was observed at the surface without diving \\
\hline Surface blow rate (SRate) & Mean number of exhalations $\min ^{-1}$ during a surfacing \\
\hline Dive-surface blow rate (SDRate) & $\begin{array}{l}\text { Mean number of exhalations } \min ^{-1} \text { averaged over the duration of a surfacing-dive } \\
\text { cycle, using the dive previous to the surfacing }\end{array}$ \\
\hline
\end{tabular}

To examine the behavioural responses of the whales, sound level variables were estimated at the tracked animal's location for each observation bin in the behavioural dataset (see Racca et al. 2015 for further details). Gray whales were exposed to an average per-pulse sound exposure level (SEL) from the seismic survey of $132 \mathrm{~dB}$ re $1 \mathrm{\mu Pa}^{2}$-s (range: 99 to $156 \mathrm{~dB}$ re $1 \mathrm{\mu Pa}^{2}-\mathrm{s}, \mathrm{n}=161$; Fig. 2). For continuous sounds related to vessel activity, whales received a mean $1 \mathrm{~s}$ SEL of $106 \mathrm{~dB}$ re $1 \mathrm{\mu Pa}^{2}$-s (75 to $137 \mathrm{~dB}$ re $1 \mathrm{\mu Pa}^{2}-\mathrm{s}, \mathrm{n}=365$; Fig. 3).

For analysis, the sound levels from the seismic source required distinct treatment for periods of seismic survey activity ('on') and periods devoid of it ('off'). To avoid a fictitious estimate of sound levels during the latter, which would have skewed the dis- tribution of received pulse levels by introducing blocks of zero values, we introduced into the model a binary (on/off) seismic survey activity indicator variable that conditioned the analysis of all acoustic pulse metrics.

\section{Independent variables}

Independent variables, used to explain variation in movement and respiration activities, were categorized into 2 classes: natural and impact variables. Natural variables included spatial, temporal, behavioural and environmental parameters (Table 2). Impact variables consisted of sound and non-sound parameters related to seismic survey and vessel activity (Table 3). 


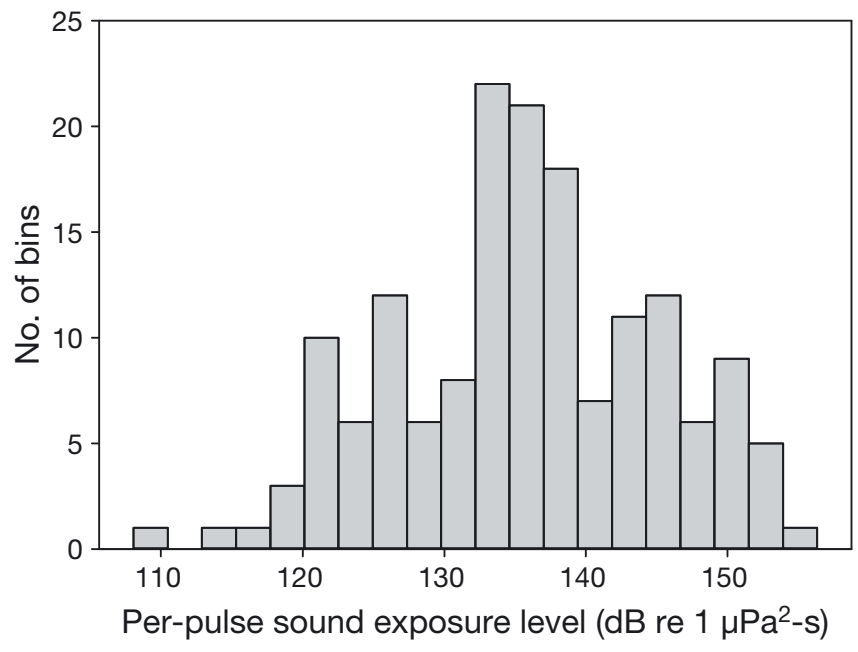

Fig. 2. Distribution of per-pulse sound exposure levels (dB re

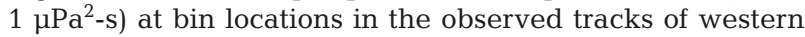
gray whales Eschrichtius robustus in the vicinity of the seismic survey

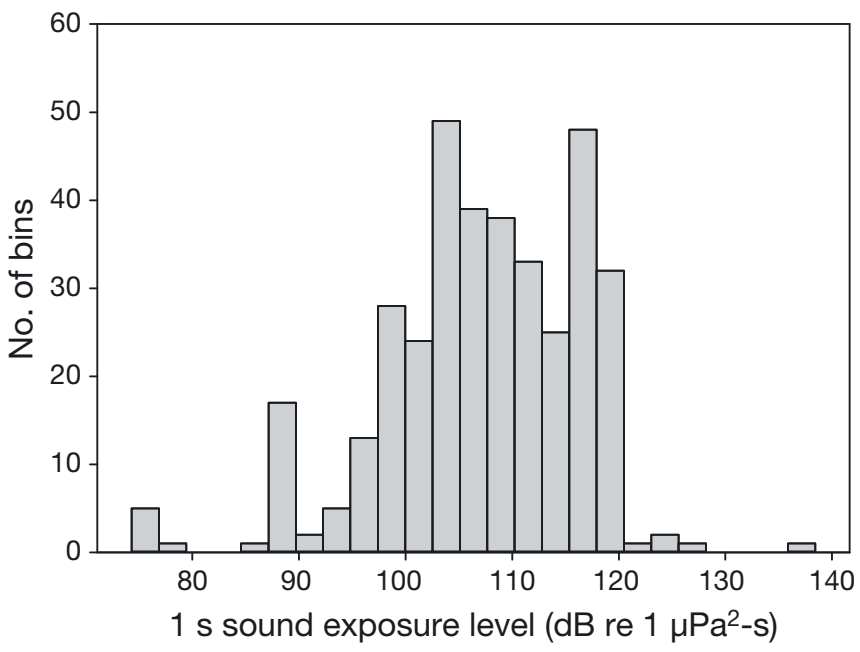

Fig. 3. Distribution of $1 \mathrm{~s}$ sound exposure levels from vessel activity (dB re $1 \mu \mathrm{Pa}^{2}$-s) at bin locations in the observed tracks of western gray whales Eschrichtius robustus in the vicinity of the seismic survey

Table 2. Natural variables used to explain variation in movement and respiration activity of western gray whales Eschrichtius robustus during the seismic survey

\begin{tabular}{|c|c|c|}
\hline Variable & Description & Coding \\
\hline Station & $\begin{array}{l}\text { Name of observation station where whale } \\
\text { was observed }\end{array}$ & $\begin{array}{l}\text { Factor with } 3 \text { levels: Blueberry Hill, North Seismic, } \\
\text { South Seismic. South Seismic is the reference level }\end{array}$ \\
\hline Day & Number of days from the start of the survey & \\
\hline Time of day & Time of the observation & $\begin{array}{l}\text { Time of the observation, coded as hours after } 00: 00: 00 \text { of } \\
\text { the same day; e.g. an observation at 3:41:15 pm on any } \\
\text { day is coded as } 15.6875\end{array}$ \\
\hline Behaviour & $\begin{array}{l}\text { Animal's behavioural state during } \\
\text { observation bin }\end{array}$ & $\begin{array}{l}\text { Factor with } 4 \text { levels: feeding, feeding/travelling, } \\
\text { travelling, mixed (other). Feeding is the reference level }\end{array}$ \\
\hline Beaufort & Sea state measured on Beaufort scale & $\begin{array}{l}\text { Factor with } 6 \text { levels: }[0],[1],[2],[3],[4],[5] \text {. } \\
{[0] \text { is the reference level }}\end{array}$ \\
\hline Visibility & Visibility conditions estimated at the time & $\begin{array}{l}\text { Factor with } 5 \text { levels: }[1],[2],[3],[4],[5] \text {. } \\
{[1] \text { is the reference level }}\end{array}$ \\
\hline $\begin{array}{l}\text { Distance } \\
\text { to station }\end{array}$ & $\begin{array}{l}\text { Distance from whale location to the onshore } \\
\text { observation station }(\mathrm{km})\end{array}$ & \\
\hline Depth & Water depth at whale location (m) & \\
\hline Tide & Predicted tide height at time of observation $(\mathrm{m})$ & \\
\hline $\begin{array}{l}\text { Wind } \\
\text { direction }\end{array}$ & Direction of the wind & $\begin{array}{l}\text { Factor with } 4 \text { levels: South ('S', 'SE', 'SES', 'SSE', } \\
\text { 'SSW', 'SW', 'SWS'), West ('W', 'WNW', 'WSW', } \\
\text { 'NWW'), East ('E', 'ENE', 'ESE', 'NEE'), North ('N', } \\
\text { 'NE', 'NNE', 'NNW', 'NW'). South is the reference level }\end{array}$ \\
\hline Humidity & Relative humidity at time of observation & \\
\hline Wind speed & Speed of the wind $\left(\mathrm{km} \mathrm{h}^{-1}\right)$ during observation & \\
\hline Swell height & $\begin{array}{l}\text { Field estimated swell height }(\mathrm{m}) \text { during } \\
\text { observation }\end{array}$ & \\
\hline
\end{tabular}

Vessel positional data as well as variables derived from those data, such as distance of closest vessel approach to a whale, were treated as continuous variables. All seismic survey-related vessels as well as other Sakhalin Energy vessels individually re- corded their positions by GPS. An Automatic Identification System (AIS) was also used during the seismic survey to record the locations of all transponderequipped vessels at distances up to $100 \mathrm{~km}$ away from the study area. Due to missing periods of AIS 
Table 3. Sound and non-sound impact variables used to explain variation in movement and respiration activity of western gray whales Eschrichtius robustus during the seismic survey

\begin{tabular}{|c|c|c|}
\hline Variable & Description & Coding \\
\hline \multicolumn{3}{|l|}{ Sound } \\
\hline Cumulative SEL & Cumulative sound exposure level for the entire track of observation & \\
\hline Per-pulse SEL & $\begin{array}{l}\text { Average sound exposure level for each pulse of seismic survey activity } \\
\text { over a } 10.5 \text { min observation interval }\end{array}$ & \\
\hline Peak SPL & $\begin{array}{l}\text { Average peak sound pressure level for each pulse of seismic survey } \\
\text { activity over a } 10.5 \text { min observation interval }\end{array}$ & \\
\hline Kurtosis & $\begin{array}{l}\text { Average sharpness of the pulse distribution with respect to normal } \\
\text { (Gaussian) distribution for each pulse of seismic survey activity over a } \\
10.5 \text { min observation interval }\end{array}$ & \\
\hline SNR & $\begin{array}{l}\text { Average ratio (in } \mathrm{dB} \text { ) between the acoustic signal and the background } \\
\text { noise for each pulse of seismic survey activity over a } 10.5 \mathrm{~min} \\
\text { observation interval }\end{array}$ & \\
\hline SEL-SV & $\begin{array}{l}1 \text { s sound exposure level received at whale's location from the seismic } \\
\text { vessel }\end{array}$ & \\
\hline SEL-PG & $\begin{array}{l}\text { 1s sound exposure level received from the nearshore behavioural } \\
\text { observation vessel (Pavel Gordienko) }\end{array}$ & \\
\hline SEL-all vessels & $\begin{array}{l}\text { Aggregate } 1 \mathrm{~s} \text { sound exposure level received from vessels in the vicinity } \\
\text { of the observed gray whale }\end{array}$ & \\
\hline \multicolumn{3}{|l|}{ Non-sound } \\
\hline Closest vessel & Distance from whale to closest vessel $(\mathrm{km})$ & \\
\hline Number of vessels & Total number of vessels within $5 \mathrm{~km}$ of the whale & \\
\hline Vessel type & Type of vessel closest to animal's location & $\begin{array}{l}\text { Factor with } 4 \text { levels: } \\
\text { seismic, behavioural, } \\
\text { support, other. Seismic } \\
\text { is the reference level }\end{array}$ \\
\hline Time since & Number of weeks since the onset of seismic survey activity & \\
\hline $\begin{array}{l}\text { Relative orientation of } \\
\text { whale to closest vessel }\end{array}$ & $\begin{array}{l}\text { Orientation of whale being observed to the closest vessel approach } \\
\text { with the distance between whale and vessel as an interaction term }\end{array}$ & \\
\hline $\begin{array}{l}\text { Relative orientation of } \\
\text { closest vessel to whale }\end{array}$ & $\begin{array}{l}\text { Orientation of the vessel to the whale being observed with the } \\
\text { distance between whale and vessel as an interaction term }\end{array}$ & \\
\hline $\begin{array}{l}\text { Relative orientation of } \\
\text { seismic vessel to whale }\end{array}$ & $\begin{array}{l}\text { Orientation of the seismic vessel to the whale with the distance } \\
\text { between the whale and sound source as an interaction term }\end{array}$ & \\
\hline $\begin{array}{l}\text { Distance to closest/ } \\
\text { seismic vessel7 }\end{array}$ & $\begin{array}{l}\text { Linear distance of whale being observed to the closest vessel } \\
\text { of approach and seismic vessel }\end{array}$ & \\
\hline
\end{tabular}

and GPS data (primarily during pre- and post seismic survey activity), the vessel position information was not complete for the duration of this study. The majority of the dataset (89\%), however, had sufficient vessel position information to estimate vessel positions continuously. In addition, there was considerably less noise-generating human activity before the seismic survey began and after it was completed.

\section{Variable treatment}

The modelling approach in this study assumed the response variables to have an approximately normal distribution. To meet this assumption, 2 variables (linearity and mean vector length) were transformed using a logistic transformation. A small constant, $0.5 \times[1-($ largest value $<1)]$, was added to all values of these variables to compute the logistic transformation when some values equalled 1.0.

The direction of movement ranged from 0 to $360^{\circ}$. Although sine/cosine representatives or circular transformation methods could have been applied, we determined that the predominant movement was in a north-south direction with little east-west movement, which is common for coastal gray whales that move parallel to shore, and therefore we categorized the direction of movement into North, East, South or West.

Collinearity among covariates was assessed by examining pair-wise Pearson correlation coefficients among all continuous natural and continuous impact 
covariates. Box-plots were used to evaluate noncontinuous natural covariates against continuous impact covariates, and vice versa. Contingency tables were computed between pairs of non-continuous variables. For all continuous variables, correlation coefficients larger than 0.60 warranted concern that natural variables were masking impact effects, or vice versa, in the models. Among pairs of variables with high collinearity, the most readily interpretable variable was retained, while the other member of the pair was dropped.

\section{Gray whale behavioural response models}

Among the fundamental analytical difficulties associated with the behavioural datasets are potential biases due to detectability, pseudo-replication and autocorrelation (Gailey et al. 2010). For example, sequential bins could be highly correlated and individuals with more bins could be over-represented in the analysis (i.e. pseudo-replication). To adjust for these sampling biases, we weighted each observation in the analysis by a value inversely proportional to the probability of obtaining that observation. Weighting is justified by the Horvitz-Thompson theorem (Horvitz \& Thompson 1952, Overton \& Stehman 1995), where weighted averages provide unbiased estimates of population means when weights are inversely proportional to the probability of including the observation. Based on this theorem, all observations in the analyses were weighted by $1 / n_{i}$, where $n_{i}$ is the number of bins in the track from animal $i$. As a result, each animal in the analyses had a total weight of 1.0. Although we attempted to account for pseudoreplication within a track, some pseudo-replication could still occur due to the same individual being tracked multiple times. Since it is impossible to identify each individual from shore, it is currently unknown how much, if any, pseudo-replication exists among different tracklines.

The response variables were modelled using mixed linear models (Pinheiro \& Bates 2000). This modelling technique was chosen due to the nature of the objectives and because autocorrelation was potentially present in the response variables. Autocorrelation within tracks was accounted for by estimating mixed linear models that assumed unstructured, constant or autoregressive dependencies in model residuals (see below). In this analysis, tracks were assumed to be the independent units of replication, not the individual observations within tracks. The models estimated changes in the responses to environmental (e.g. depth, wind speed) and impact covariates (e.g. received sound levels, vessel distances). The mixed linear models for a particular response took the following form:

$$
\mathbf{y}_{i}=\mathbf{X}_{i} \boldsymbol{\beta}+\mathrm{b}_{i}+\boldsymbol{\varepsilon}_{i}
$$

where $\mathbf{y}_{i}$ is the vector of responses for track $i, \boldsymbol{\beta}$ is a vector of fixed effects coefficients, $b_{i}$ is a random effect associated with the $i^{\text {th }}$ track that is assumed to be normally distributed, $\mathbf{X}_{i}$ contains the (fixed) covariates associated with track $i$ and $\boldsymbol{\varepsilon}_{i}$ is the vector of random within-track errors that is assumed to follow a normal distribution with mean 0 and covariance $\Sigma$. The error matrix $\Sigma$ was assumed to have either an unrestricted, constant or auto-regressive structure (Pinheiro \& Bates 2000). The unstructured correlation model assumed no structure in $\Sigma$ (except symmetry) and estimated separate covariance for each pair of errors within a track. The constant correlation model assumed that correlation among all pairs of errors was equal regardless of the time differences between them. The auto-regressive correlation structure assumed that correlation between errors associated with observations at time $a$ and $b$ was $\rho^{|a-b|}$, where $\rho$ is the parameter to be estimated. All effects were estimated with generalized estimating equations using the R function 'Ime()' available in the 'nlme' package (R Development Core Team 2010, http:// cran.r-project.org/web/packages/nlme/index.html).

Model selection was based on a stepwise selection procedure that relied on the Bayesian Information Criterion (BIC). BIC, rather than Akaike's Information Criterion (AIC), was chosen as the measure of variable utility because it generally yields a more parsimonious model. Both forward and backward step selection was used to include natural and/or impact effects. The initial model contained an intercept only. BIC was computed after addition of each variable, and the variable that reduced BIC the most was added to the current model (forward step). Any variable already in the model that did not cause BIC to increase when removed was eliminated from the model (backward step). The final model was determined after the cycle of forward and backward steps was repeated and BIC could not be further reduced. Standardized residual plots were inspected to assess model fit.

\section{Statistical power}

Power analyses were conducted to examine the statistical power of the models that were applied here to 


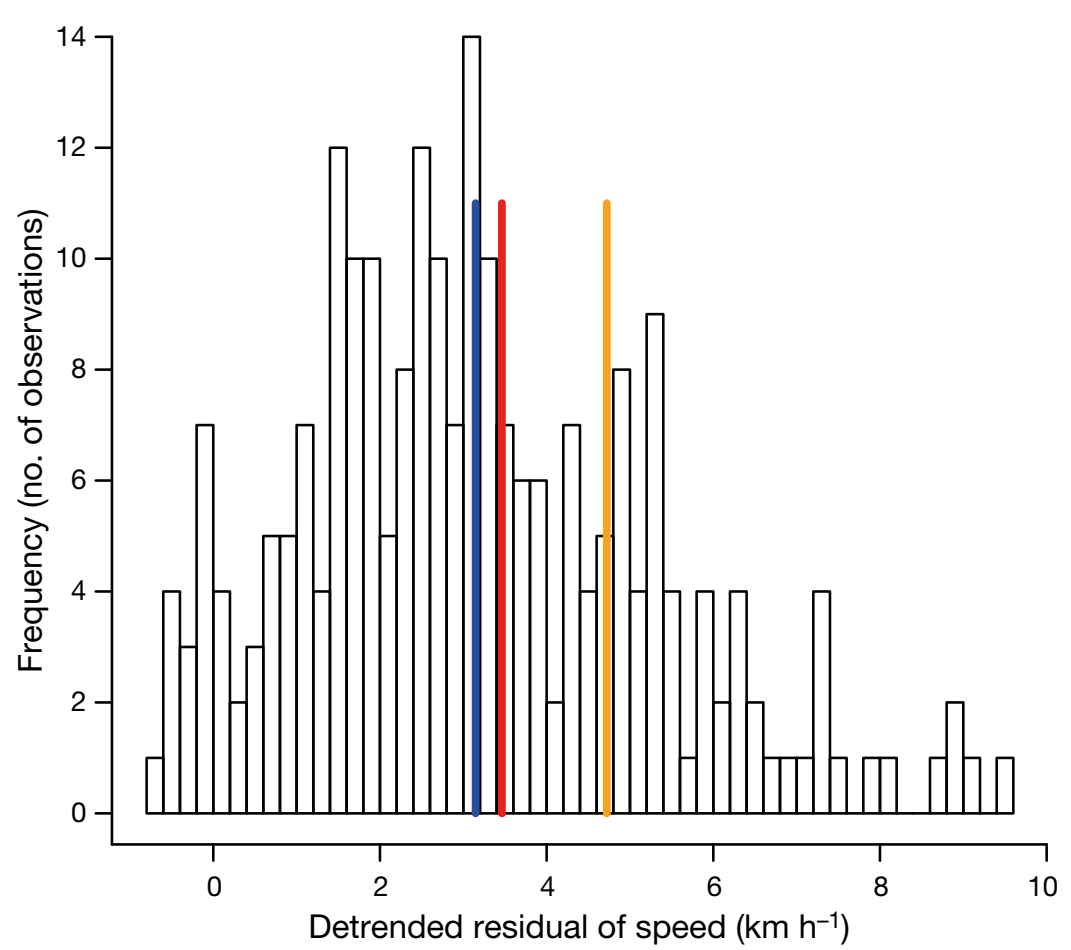

Fig. 4. Distribution of de-trended observations and assumed effect sizes used to assess statistical power of a mixed linear model to detect anthropogenic effects on western gray whales Eschrichtius robustus. Vertical blue line: mean speed $\left(3.15 \mathrm{~km} \mathrm{~h}^{-1}\right)$ when seismic survey activities were not being conducted. The other lines mark the $10 \%$ (red line, $3.46 \mathrm{~km} \mathrm{~h}^{-1}$ ) and $50 \%$ (orange line, $4.72 \mathrm{~km} \mathrm{~h}^{-1}$ ) increase when seismic survey activities were occurring. The 10 or $50 \%$ increase in mean speed was assumed to occur when peak sound pressure level (SPL) increased from 121 to $150 \mathrm{~dB}$ re $1 \mu \mathrm{Pa}$ observed whale tracks. When a track was chosen during re-sampling, all bins associated with it were included. Thus, simulated data sets contained $\mathrm{n}$ tracks and $\sim 6.7 \mathrm{n}$ bins. For each simulated dataset, natural and anthropogenic effects that might be present in the observed data were eliminated by computing residuals of the response in a mixed linear model that contained both natural and anthropogenic effects. To illustrate, Fig. 4 depicts the distribution of residuals from a mixed linear model containing natural and anthropogenic effects fitted to the re-sampled data, after adding the mean level of speed back in. In other words, Fig. 4 demonstrates the distribution of speed, after subtracting the effects of natural (distance to station and swell) and anthropogenic variation (presence of seismic pulses and their peak sound pressure level, SPL). The distribution of residuals around the response's grand mean represents inherent and random variation of the response when no effects of any kind were present. These values (grand mean plus residual) were termed 'de-trended observations'.

detect population-level changes in gray whale movement and respiration activity due to increased exposure to seismic survey sounds. These power analyses estimated the number of independent samples needed to detect small and large changes in the response variables associated with seismic survey sounds. We used data collected during periods with no noise-generating human activity as a guide for natural variation and simulated observations containing known-size anthropogenic effects. These simulated observations were then analysed by the mixed linear model procedures described above and detection of the effects was recorded. Through repetitive simulation and analysis, we were able to assess the statistical power of a range of sample sizes and significance levels. We simulated 10 and $50 \%$ increases in the mean of each response variable when seismic survey sound increased from low to mean levels. We estimated power under significance levels of $\alpha=0.05$. As a benchmark, we report the sample size that achieves a power of $80 \%$ for a particular effect.

For every sample size, n, we simulated data by first re-sampling, with replacement, $\mathrm{n}$ tracks from the 59
Simulated data sets containing positive anthropogenic effects were constructed from the de-trended observations as follows. The desired effect size was calculated as either 10 or $50 \%$ of the de-trended observation's grand mean. The grand mean (i.e. no effect) was $3.15 \mathrm{~km} \mathrm{~h}^{-1}$ and a $10 \%$ increase in speed was $3.46 \mathrm{~km} \mathrm{~h}^{-1}\left(=1.1 \times\left[3.15 \mathrm{~km} \mathrm{~h}^{-1}\right]\right)$ (Fig. 4). This increase was then converted into a slope coefficient using the difference between minimum and mean peak SPL when the seismic source was operating. Therefore, the coefficient for change in response per unit change in peak SPL was:

$$
\beta_{1}=
$$

mean response[seismic present] - mean response[seismic absent] mean SPL[seismic present] - min SPL[seismic present]

$$
=\frac{\text { Effect size } \times(\text { mean response })}{\text { mean } \mathrm{SPL}-\min \mathrm{SPL}}
$$

In Fig. 4, we assumed either a 10 or $50 \%$ increase in average speed (to 3.46 or $4.72 \mathrm{~km} \mathrm{~h}^{-1}$, respectively) when peak SPL at the whale's location increased from $121 \mathrm{~dB}$ re $1 \mu \mathrm{Pa}$ (the minimum observed peak $\mathrm{SPL}$ ) to $150 \mathrm{~dB}$ re $1 \mu \mathrm{Pa}$ (the average observed peak 
SPL). Under the $10 \%$ change assumption, whale speeds increased $0.011 \mathrm{~km} \mathrm{~h}^{-1}$ per dB increase in peak SPL. Similar assumptions and computations were made for the other response variables to establish the 'true' relationship between the response and seismic survey sound levels.

Finally, residuals from the model containing natural and anthropogenic effects were added to the 'true' relationship to establish a simulated 'fitting' data set. A model containing anthropogenic effects was then re-fit to the 'fitting' dataset, and the coefficient of peak SPL was tested for significance using the $t$ statistic ( $t=$ coefficient $/ \mathrm{SE}$ ). If the coefficient was significantly different from zero according to the $\alpha$-level under consideration, then an effect of peak SPL on the parameter was considered to have been detected.

By repeatedly sampling the residuals and adding them to the 'true' relationship to re-construct 'fitting' data sets, fitting a model containing simulated peak SPL values and observing whether a positive slope was detected, it was possible to compute power for a particular sample size as a proportion of rejections among such iterations. The number of iterations used for each simulation was 100 . Due to variation inherent in re-sampling tracks, the entire process of resampling tracks, re-constructing 'true' values and running 100 iterations of detection simulations was repeated 10 times for each sample size. Reported power was the average of these 10 values.

\section{RESULTS}

\section{Effort}

A total of 35 seismic lines were acquired (i.e. completed) from 17 June to 2 July 2010 (see Bröker et al. 2015). Due to mitigation, weather or technical issues, some lines were only partially acquired, which resulted in 56 attempts to acquire all 35 seismic lines. The time needed to acquire a seismic line was typically $\sim 2.5 \mathrm{~h}$ with a subsequent $\sim 3 \mathrm{~h}$ period of no seismic survey activity due to the line-turn (Bröker et al. 2015). Behavioural data were collected pre- (8 d), during (10 d) and post (2 d) seismic survey activity from 6 June to 11 July 2010 with 179 h of effort. A total of 59 tracklines (395 bins) and 36 focal follows (214 bins) were used in the analyses. Certain variables could not be measured in some focal bins, primarily because focal animals did not dive during the observation period, or other variables were unavailable. Consequently, the actual number of bins used for estimation varied slightly depending on the focal response variable being analysed.

\section{Response variables}

The movement response variables of range and mean vector length were excluded from the analyses since those variables were highly correlated (Pearson's $r>0.90$ ) with speed and linearity, respectively. The association between speed and range could be substantially different in some contexts. For example, an animal moving at relatively high speeds in random directions would likely not move far spatially, indicating high speeds but low range indices. However, for the gray whales in this study, low speeds tended to indicate that an animal was feeding in a localized area, which resulted in small geographic range indices, while higher speeds tended to be more directional with higher range indices, resulting in high correlations between these 2 variables. The directionality indices of linearity and mean vector length are similar (linearity based on distances and mean vector length on turning angles). We chose linearity as a representative directionality response variable.

For respiration response variables, the surface blow rate (SRate; number of blows per surface time) and respiration interval were correlated (Pearson's $\mathrm{r}=$ $-0.78)$, indicating that with shorter intervals between respirations, SRate also decreased. With increased surface time, the number of blows at the surface (Pearson's $r=0.83$ ) and time at the surface (Pearson's $r=0.77$ ) also increased. Recognizing that there are some relationships among respiration response variables, we chose to examine all respiration response variables so that our study would be comparable to other gray whale behavioural studies (e.g. Würsig et al. 1986, Guerrero 1989, Stelle et al. 2008). No correlation was found among any of the movement and respiration response variables.

\section{Responses in movement}

From the number of potential explanatory variables considered, behavioural state was the largest predictor of gray whale movements. Behavioural state explained a significant amount of variation for linearity, reorientation rate, speed and relative orientation to the seismic vessel. Compared to the feeding state, the models suggested that whales increased their speed, linearity and relative orientation to the seis- 
Table 4. Model results for western gray whale Eschrichtius robustus movement response variables. Each row represents a model with the response variable (see Table 1 for abbreviations), followed by the intercept $\left(\beta_{0}\right)$ in the next column and explanatory variables that entered into the model in subsequent columns (Behavioural state abbreviations, FT: feeding/travelling; T: travelling; M: mixed). See Table 2 for further explanation of variables. Numbers in each explanatory column represent the coefficients in the model, with bold representing significant coefficients $(\mathrm{p}<0.05)$ and other coefficients in regular print indicating variables that entered into the final model but were nonsignificant $(\mathrm{p}>0.05)$

\begin{tabular}{|c|c|c|c|c|c|c|c|c|c|c|c|c|c|}
\hline \multirow{2}{*}{$\begin{array}{l}\text { Response } \\
\text { variable }\end{array}$} & \multirow[t]{2}{*}{$\beta_{0}$} & \multirow{2}{*}{$\begin{array}{c}\text { Humi- } \\
\text { dity }\end{array}$} & \multirow{2}{*}{$\begin{array}{c}\text { Dist_- } \\
\text { Station }\end{array}$} & \multirow[t]{2}{*}{ Depth } & \multicolumn{2}{|c|}{ Closest vessel } & \multicolumn{3}{|c|}{ Behavioural state } & \multicolumn{4}{|c|}{ Relative orientation (CV vessel) } \\
\hline & & & & & BoatPres & CV_Dist & FT & $\mathrm{T}$ & M & $\begin{array}{c}\text { Sin } \\
\text { (Orient) }\end{array}$ & $\begin{array}{c}\text { Cos } \\
\text { (Orient) }\end{array}$ & $\begin{array}{c}\text { Sin } \\
\text { (Orient:Dist) }\end{array}$ & $\begin{array}{c}\text { Cos } \\
\text { (Orient:Dist) }\end{array}$ \\
\hline Acc & -0.02 & 0 & & & & & & & & & & & \\
\hline distshore & 0.87 & & 0.21 & & 0.72 & -0.05 & & & & & & & \\
\hline Lin (logit) & 0.81 & & & & & & 1.87 & 3.17 & 1.75 & & & & \\
\hline $\mathrm{RR}$ & 27.20 & & 1.17 & & & & -14.80 & -22.00 & -15.90 & & & & \\
\hline Spd & -0.40 & & 0.56 & & & & 1.46 & 3.81 & 2.29 & & & & \\
\hline mDir & 1.15 & -0.006 & & 0.01 & & & & & & & & & \\
\hline ROW_CV & 98.50 & & & & & -2.57 & & & & 3.43 & -15.4 & 0.16 & 1.32 \\
\hline ROW_SV & 67.90 & & & & & & 30.34 & 8.92 & 10.08 & & & & \\
\hline
\end{tabular}

mic vessel (moving away) and decreased their reorientation rate when travelling. Feeding/travelling coefficients were typically between those of the referenced feeding state and travelling behaviour (Table 4). Humidity entered into 2 models (acceleration and direction of movement). However, the coefficients were small $(<0.007)$. As a function of distance from the observation platform, the distance from shore as well as the animal's speed and orientation generally increased. The direction of movement also became slightly more linear as a function of water depth (Table 4).

Gray whale movement patterns were not significantly associated with any of the sound exposure covariates. Two non-sound related impact variables, however, were significantly associated with whale distance from shore and relative orientation. The distance of the closest vessel approach to whales was associated with the whales' distance from shore. This would be expected given that whales observed farther from shore were closer to the vessel activity, which was generally offshore of the whales' feeding area.

The closest vessel's orientation with respect to the whale was found to alter the whale's orientation to the vessel, suggesting some level of vessel-whale interaction effect. When the closest vessel was within $\sim 12 \mathrm{~km}$, the whale oriented primarily perpendicular to the vessel regardless of the vessel's orientation (Fig. 5). When the closest vessel was within $\sim 5 \mathrm{~km}$ and oriented perpendicular to or away from the whale (lower right corner of Fig. 5), the whale was generally oriented away from the vessel. As the vessel moved away from the whale and became more oriented away from the whale, the whale changed orientation from perpendicular to towards the vessel (upper right corner of Fig. 5).

\section{Responses in respiration}

Despite behavioural state being the best predictor in the movement models, only one respiration response variable was found to be associated with behavioural state. While feeding, gray whales exhibited an increased SRate compared to that performed while feeding/travelling and travelling. Wind speed and swell height were found to explain a portion of the variation in the amount of time whales spent at the surface as well as the number of blows seen at the surface. These results suggest that as wind speed increased, the surface time and number of blows observed decreased. As swell increased, the surface time and number of blows observed also increased. The portion of the time whales were detected during an observation bin was also found to be associated with increased swell height. Water depth has been consistently observed to be an important explanatory variable for dive time. The observed dive duration increases with water depth (Table 5).

As with the movement response variables, no sound-related impact variables were found to be associated with any of the respiration response variables. The number of vessels within $5 \mathrm{~km}$ was the only non-sound related impact variable that entered into any of the respiration models. This variable was associated with the dive-surface blow rate (DSRate), which suggests that whales were cycling through their dive-respiration-surfacing cycles more rapidly as the number of vessels within $5 \mathrm{~km}$ increased. 


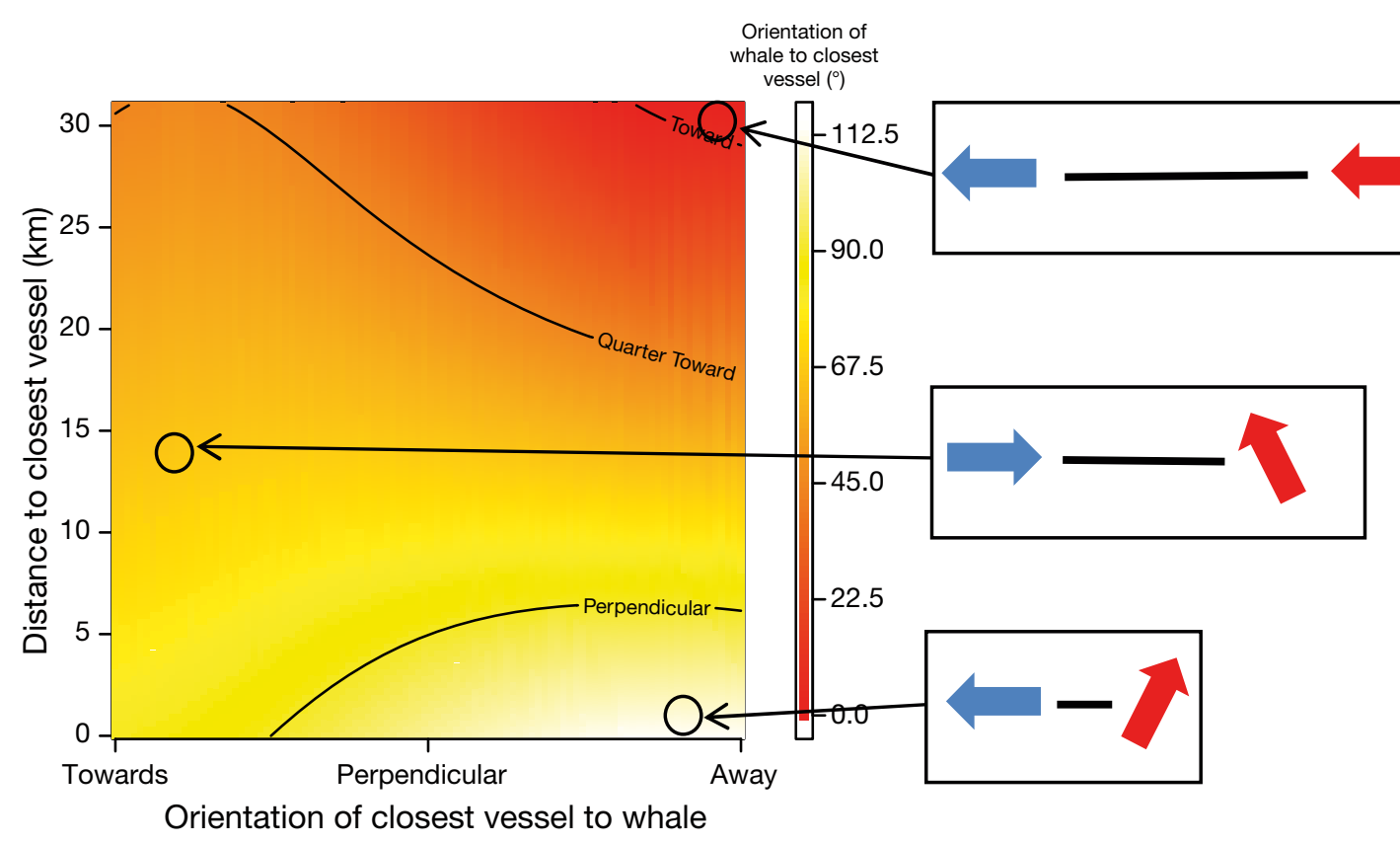

Fig. 5. Relative orientation of western gray whales Eschrichtius robustus to the closest vessel of approach and the vessel's orientation to the whale as predicted by the final model for relative orientation (left). Three relative orientations from the left main panel are illustrated on the smaller panels to the right, with blue arrows representing the vessel, red arrows the whale, and bars the distance (not to scale) between the 2

\section{Statistical power}

Power curves, representing the power to detect a $10 \%$ change in speed for a given sample size, are illustrated in Fig. 6. The estimated number of whale tracks necessary to detect a 10 and $50 \%$ change in each response variable with $80 \%$ power when $\alpha=$ 0.05 is shown in Table 6.

Power to detect a $10 \%$ change in the mean of a response variable at the $\alpha=0.05$ level ranged from 398 to $>7000$ tracks (Table 6). Excluding the more extreme estimates (398 for distance from shore and 7000 for acceleration), the average number of tracks needed to detect a $10 \%$ change in the variable was approximately 1200 . The sample size to detect a $50 \%$ change in track parameters was roughly an order of magnitude smaller than the sample size necessary to detect a $10 \%$ change. Excluding distance from shore and acceleration, the average number of tracks needed to detect a $50 \%$ change in the remaining 6 track parameters was approximately 50 (Table 6).
For respiration response variables, the number of samples required to detect a $10 \%$ change in a focal parameter at the $\alpha=0.05$ level ranged from 319 to 1415 (Table 7). Excluding the 2 extremes (1415 for surface time and 319 for DSRate), the average sample size needed to detect a $10 \%$ change with $80 \%$ power for the respiration variables was approximately 550. For a larger effect size (50\% change), the number of focal follows needed ranged from 15 to 57 (Table 7) with a mean of approximately 27.

Table 5. Summary of model results for respiration response variables of western gray whales Eschrichtius robustus. Each row represents a model with the response variable in the first column, intercept $\left(\beta_{0}\right)$ in the next column and explanatory variables that entered into the model in subsequent columns (Behavioural state abbreviations FT: feeding/travelling; T: travelling; M: mixed). See Table 3 for further explanation of variables; NVes: no. of vessels. Numbers in each explanatory column represent the coefficients in the model with bold representing significant coefficients $(\mathrm{p}<0.05)$ and coefficients in regular print indicating variables that entered into the model but were non-significant $(\mathrm{p}>0.05)$

\begin{tabular}{|c|c|c|c|c|c|c|c|}
\hline \multirow[t]{2}{*}{ Response variable } & \multirow[t]{2}{*}{$\beta_{0}$} & \multirow{2}{*}{$\begin{array}{l}\text { Wind } \\
\text { Spd }\end{array}$} & \multirow[t]{2}{*}{ Swell } & \multirow[t]{2}{*}{ Depth } & \multicolumn{2}{|c|}{ Behavioural state } & \multirow[t]{2}{*}{ NVes } \\
\hline & & & & & FT $\quad \mathrm{T}$ & M & \\
\hline Respiration interval & 0.44 & & & & & & \\
\hline Surface time & 0.97 & -0.02 & 0.29 & & & & \\
\hline Dive time & 1.38 & & & 0.10 & & & \\
\hline Number blows/surfacing & 2.09 & -0.06 & 0.51 & 0.15 & & & \\
\hline Surface blow rate & 5.03 & & & & $-0.11-\mathbf{- 1 . 1 5}$ & -0.55 & \\
\hline Dive surface blow rate & 0.93 & & & & & & 0.08 \\
\hline Time at surface & 15.77 & & 13.83 & & & & \\
\hline
\end{tabular}




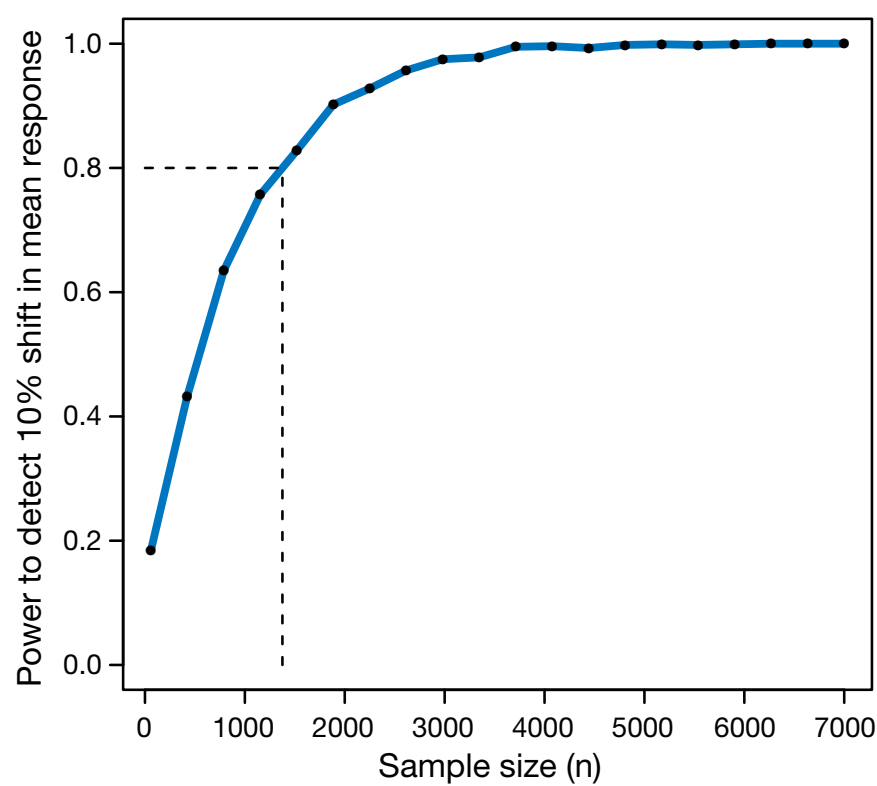

Fig. 6. Power to detect a $10 \%$ change in gray whale Eschrichtius robustus speed. Dashed lines highlight sample size required to detect a $10 \%$ change with $80 \%$ power when $\alpha=0.05$

\section{Individual responses to seismic survey activity}

Although our analyses found little association between gray whale behaviour and seismic survey activity, the analyses assumed all animals would react in a similar manner when exposed to the activity. In addition, the analyses suffered from limited sample sizes to detect moderate to subtle changes in behaviour. Observations of gray whales during seismic survey exposure did document several individual responses to the activity. As these individual responses are critical towards understanding gray whale behaviour when confronted with human activities, we provide 2 case examples to document these behavioural changes.

On 1 July 2010, an individual was observed travelling from the south at relatively high speeds (mean $=8.1 \mathrm{~km} \mathrm{~h}^{-1}$, range: 6.1 to $9.9 \mathrm{~km} \mathrm{~h}^{-1}$ ). The animal was initially observed after seismic acquisition activity had commenced. The individual was travelling parallel to shore towards the behavioural mitigation A-zone. During this parallel-to-shore travel, the sound exposure (range: 143 to $151 \mathrm{~dB}$ SEL) experienced by the animal gradually increased, as the seismic vessel was moving more rapidly than the animal. Slightly before a shut-down would have been ordered due to a gray whale's presence in the A-zone, the individual deviated from its path paral-
Table 6. Estimated sample size ( $\mathrm{n}=$ number of western gray whale tracks) necessary to detect a 10 or $50 \%$ change in each response variable with $80 \%$ power when $\alpha=0.05$

\begin{tabular}{|lrr|}
\hline Parameter & \multicolumn{2}{c|}{ Sample size (n) } \\
& $10 \%$ & $50 \%$ \\
& change & change \\
\hline Acceleration & $>7000$ & $>300$ \\
Distance from shore & 398 & 23 \\
Linearity & 1717 & 62 \\
Reorientation rate & 1300 & 52 \\
Speed & 1376 & 54 \\
Relative orientation to closest vessel & 908 & 49 \\
Relative orientation to seismic vessel & 848 & 23 \\
Direction of movement & 1144 & 43 \\
\hline
\end{tabular}

Table 7. Estimated sample size $(\mathrm{n}=$ number of western gray whale focal-animal follow sessions) necessary to detect a 10 or $50 \%$ change in focal follow parameters with $80 \%$ power when $\alpha=0.05$

\begin{tabular}{|lrc|}
\hline Parameter & \multicolumn{3}{c|}{$\begin{array}{c}\text { Sample } \\
10 \%\end{array}$} & \begin{tabular}{c}
\multirow{2}{*}{ cize (n) } \\
change
\end{tabular} & change \\
\hline Respiration interval & 552 & 27 \\
Surface time & 1415 & 57 \\
Dive time & 338 & 16 \\
Number of blows/surfacing & 415 & 18 \\
Surface blow rate & 364 & 18 \\
Dive surface blow rate & 319 & 15 \\
Time at surface & 1111 & 39 \\
\hline
\end{tabular}

lel to the shoreline and began moving toward shore, where sound exposure presumably decreased. The animal continued its high-speed travel northward into water depths of $6 \mathrm{~m}$ and eventually moved farther offshore at the end of the seismic acquisition activity, likely due to the presence of a sand bar associated with the mouth of the lagoon that commonly prevents individuals, including mothers with calves, from continuing a parallel coastal movement in this area (Fig. 7). Unfortunately, the behaviour of the animal was not observed prior to the onset of seismic acquisition activity.

On 29 June 2010, an individual was observed feeding/travelling in a northeast direction prior to the onset of seismic acquisition activity. The whale's mean speed of travel during this period was $2.1 \mathrm{~km}$ $\mathrm{h}^{-1}$. At the initiation of seismic source ramp-up procedures (a progressive increase in power before the start of an acquisition line), the individual transitioned from feeding/travelling in a northeast direction to travelling in a northwest direction at speeds ranging 


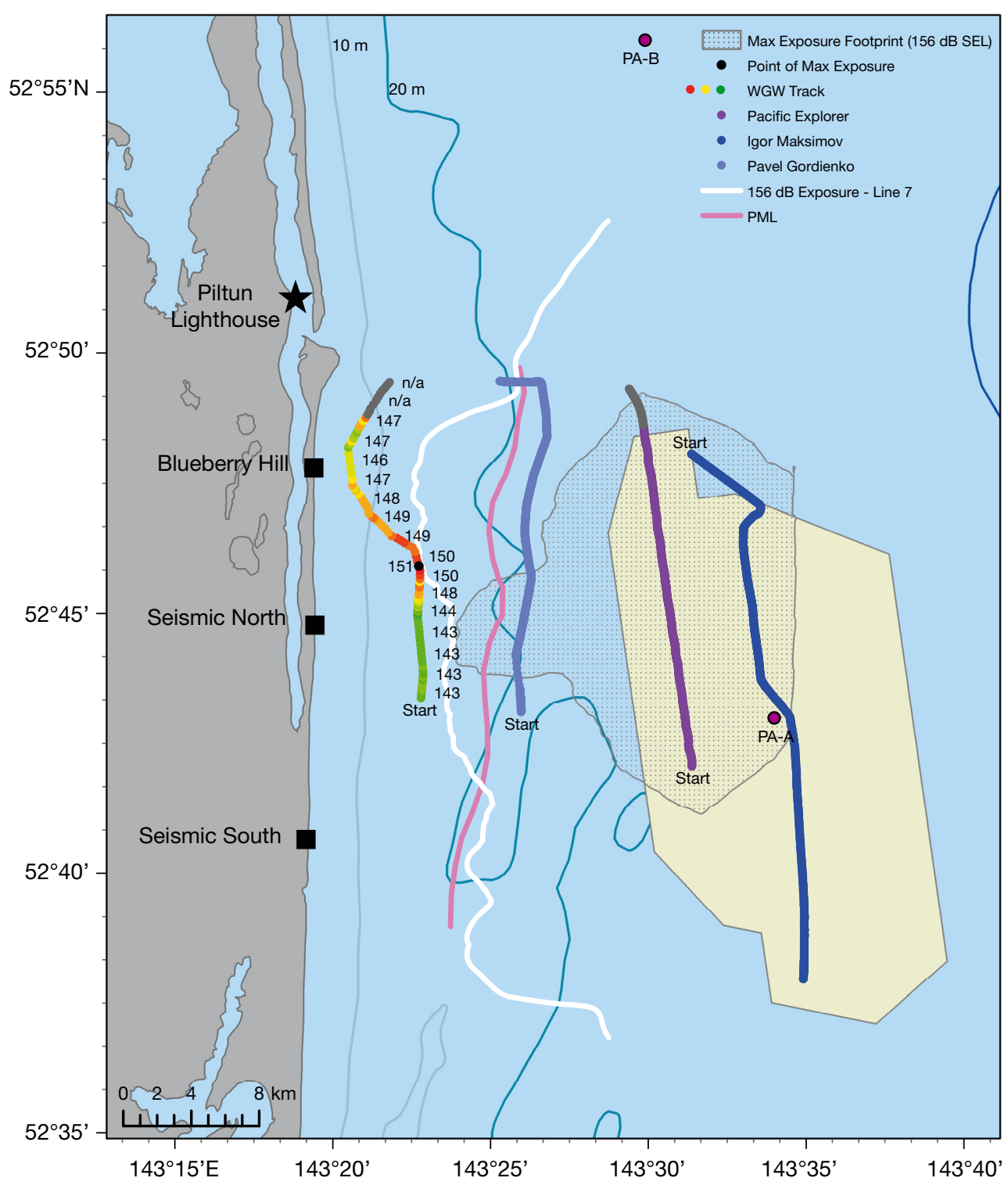

Fig. 7. Case example of a western gray whale (WGW; Eschrichtius robustus) responding to seismic survey activity on 1 July

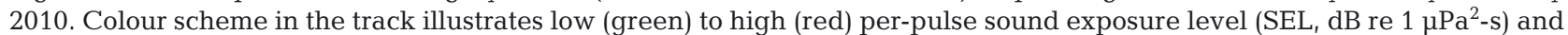
periods when no seismic acquisition was being conducted (gray, n/a). Dark blue, purple and light blue lines illustrate vessel activity during seismic acquisition. Gray polygon: acoustic footprint at the time of maximum per-pulse SEL at the animal's location ( 151 dB re $1 \mu \mathrm{Pa}^{2}$-s, black dot). See Fig. 1 for further explanations

from 5.2 to $9.8 \mathrm{~km} \mathrm{~h}^{-1}$. The estimated sound exposure at the animal's location ranged from 127 to $139 \mathrm{~dB}$ SEL. Unlike the previous example where the animal was observed to avoid increased sound exposure, this individual moved in a direction that would have increased its level of exposure. At the end of the observation period, the animal entered into the behavioural mitigation A-zone and a precautionary shut-down of the seismic source was ordered (Fig. 8). The animal continued to move farther offshore and out of visual range of the shore-based teams.

\section{DISCUSSION}

\section{Natural influences on gray whale behaviour}

The behavioural activity of the animal was the largest 'natural' predictor of gray whale movements and respirations in the feeding area. In similar analyses of independent datasets, Gailey et al. (2007b, 2010) also found that different behavioural activities of gray whales entailed changes in movement patterns of speed, reorientation rate and linearity. In this 


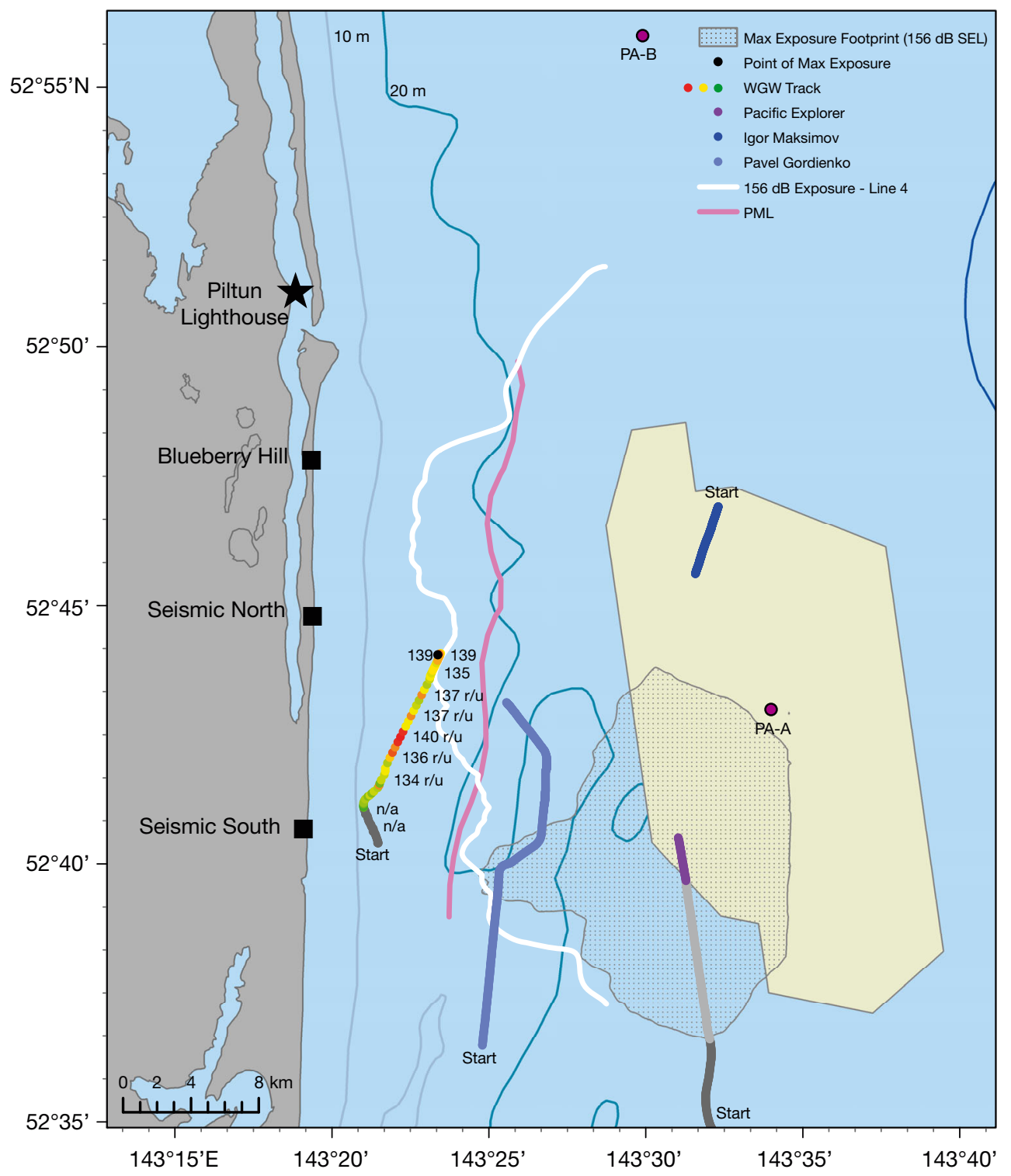

Fig. 8. Case example of a western gray whale (WGW; Eschrichtius robustus) responding to seismic survey activity on 29 June

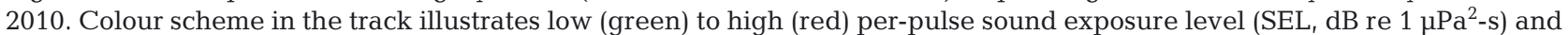
periods when no seismic acquisition was being conducted (gray, n/a). The postfix r/u identifies sound levels for the period in which the seismic source was being ramped up to full power. Dark blue, purple, and light blue lines illustrate vessel activity during seismic acquisition. Gray polygon: acoustic footprint at the time of maximum per-pulse SEL at the animal's location ( $139 \mathrm{~dB}$ re $1 \mathrm{\mu Pa}^{2}-\mathrm{s}$, black dot). See Fig. 1 for further explanations

study, however, only SRate was significantly associated with the behavioural activity of the animal. Gailey et al. $(2007 b, 2010)$ found SRate to be influenced by behavioural activity as well, but those studies also identified respiration interval and surface time response variables as exhibiting change (shorter respiration intervals and surface times while feeding compared to travelling), depending on the activity of the animal.

Interestingly, dive duration was not found, either in this study or in previous analyses of gray whale behaviour, to change significantly with behavioural state (Gailey et al. 2007b, 2010). Dive duration has, however, been consistently observed to be longer in water of greater depths. Shore-based observation offers only limited opportunities to record behaviour of whales in deeper waters. It has been hypothesized that the shorter dive durations observed off Sakhalin compared to other gray whale studies is due to the very shallow depth of the whales' nearshore feeding area there (Weller et al. 1999). Würsig et al. (1986) observed a general increase in gray whale dive time 
in deeper (>20 m) water. Dolphin (1987) also found correlations between humpback whale Megaptera novaeangliae dive duration and depth of prey patches, and the benthic method of feeding of gray whales has been noted to influence dive duration, surface time and SRate in a number of studies (Würsig et al. 1986, Guerrero 1989, Mallonee 1991, Hawkinson 1992, Stelle et al. 2008). This relationship, therefore, may be related to the extended time required to reach a prey source in deeper waters.

\section{Anthropogenic influence on gray whale behaviour}

Behavioural changes in response to seismic survey and other anthropogenic sounds have been noted for a number of cetacean species (Richardson \& Würsig 1995, Southall et al. 2007). Behavioural responses to anthropogenic sound can be variable in duration (short-term vs. long-term) and spatial scale (localized vs. large scale). For example, bowhead whales Balaena mysticetus respond to industrial sounds at both local $(<10 \mathrm{~km})$ and broad scales $(>70 \mathrm{~km})$ (Richardson et al. 1985, 1986, Ljungblad et al. 1988, Richardson \& Malme 1993). On their breeding grounds in Mexico, gray whales are believed to have abandoned entire lagoon systems in response to increased vessel traffic (Bryant et al. 1984). On feeding grounds, gray whales respond behaviourally and spatially to both pulse (seismic survey) and continuous sounds (vessel traffic, platform installation, dredging, etc.) (Weller et al. 2002, Gailey et al. 2007a,b, 2010, Yazvenko et al. $2007 \mathrm{a}, \mathrm{b})$.

The present study examined whether individuals exposed to seismic survey sound and/or sounds of vessel activity exhibited consistent movement or respiration responses. There is considerable variability in cetacean behaviour in response to sound-generating human activities which could be dependent on the context of the exposure compared to the overall sound level (Beale \& Monaghan 2004, Beale 2007, Ellison et al. 2012). In our study we attempted to consider a number of acoustic metrics as well as the distance of an activity from the animal, orientation of the activity relative to the animal and the animal's orientation relative to the activity as contextual aspects. We were unable to detect significant population-level behavioural responses to seismic survey activity, although individual responses were observed. Therefore, this study failed to reject the null hypothesis that there were no population-level behavioural impacts on the gray whales from exposure to sounds from the seismic survey or the nearshore vessel activity.
We found that vessel activity explained variation in the relative orientation of the whales and their DSRate. Swartz \& Jones (1979) found that vessels moving erratically or at high speeds in the Baja California wintering lagoons occasionally caused gray whales to swim away rapidly, but there was little or no whale response to slow-moving or anchored vessels. Similarly, Bogoslovskaya et al. (1981) found that on summer feeding grounds, gray whales fled when Soviet catcher boats approached to within 350 to $550 \mathrm{~m}$, but generally paid no attention to vessels at distances $>550 \mathrm{~m}$. It is possible that the whales observed in that study had been sensitized to catcher boats due to negative experiences. Earlier studies of gray whales at Sakhalin documented behavioural responses (increased accelerations, high speeds and distances from shore) to vessel activity (Gailey et al. 2007b, 2010). However, the present study is the first to examine the interactions between relative orientations of the animal and the closest vessel of approach. Chronic exposure to these disrupting activities can result in displacement from prime habitat or to tolerance of the activity in order to remain in the habitat (Bejder et al. 2009).

The absence of a detectable behavioural response to the seismic survey could have been the result of an effective mitigation and monitoring plan (Bröker et al. 2015) that limited the whales' exposure to disturbing sound levels. It must also be acknowledged, however, that the power analyses above revealed that the sample sizes in our study were inadequate for detecting small or moderate behavioural changes in whale movement and respiration patterns in response to anthropogenic sounds. Low sample sizes were a result of a key element of the mitigation strategy, i.e. conducting the seismic survey as early in the season as possible to limit the acoustic exposure to a smaller number of whales and avoid disturbing mother-calf pairs, which tend to be the last group to arrive on the feeding grounds. Only one mother-calf pair was observed during the seismic survey, which suggests the early start of the operations was effective in reducing exposure of these sensitive individuals at a critical time in their life cycle.

\section{Limitations}

In this study we were not concerned with effects on individuals, but rather population-level impacts. In other words, one individual's obvious reaction to sound or vessel proximity would not be of the same relevance and concern as the more subtle and consistent reactions of many individuals. The analytical 
concern is whether sufficient data were available in relation to a specific dose of exposure to determine whether there was or was not a behavioural reaction.

An examination of statistical power is essential to place results into context. Our power analysis estimated that approximately 1200 tracks would be needed to identify a $10 \%$ change in response variables with $80 \%$ probability using a significance level of $5 \%$. With larger effect sizes, such as whales moving at much higher speeds when exposed to increasing sound levels, the sample sizes required to detect the associations of swim speed with sound are lower.

With a modest sample size of 59 tracks, this study had sufficient power to detect large effects, such as a changes in gray whale speed greater than $50 \%$ of their 'normal' speed, but the study was more limited in its power to detect moderate to subtle shifts in movement and respiration. During a seismic survey conducted in the same region in 2001, several movement and respiration responses were found to be significantly associated with higher received sound levels (Gailey et al. 2007a). Due to the longer duration and timing of that seismic survey, combined with a different analytical approach (see below), the sample sizes yielded approximately 500 bins for variables of movement and 240 bins for respiration. Consequently, Gailey et al. (2007a) had more statistical power and thus higher probability of detecting moderate changes in gray whale behaviour due to sound exposure from the 2001 seismic survey. Gailey et al. (2007a), however, used each bin as the sampling unit rather than weighting the bins to the individual as done here. Arguably this could have biased the results of the earlier study towards individual responses or, alternatively, provided greater statistical power to detect population-level responses.

The mitigation measures adopted during the 2010 seismic survey were designed to minimize the duration of the survey, to complete it as early in the feeding season as feasible and minimize sound levels to which the whales would be exposed. The strategy arguably resulted in fewer whales being exposed. However, by limiting the sample size of observations, it also limited the power of this study to assess the animals' behavioural responsiveness to pulse sounds. With such limited sample sizes, it is difficult to test a null hypothesis of no impact.

Given the low sample size, a more successful approach might be to develop alternative hypotheses which do not assume no impact but rather assume an impact of a specified effect size for a particular parameter. Under certain assumptions, one could test whether seismic survey activity had an effect on speed, for example, to obtain a more sensitive indicator of impact given the limitations of sample size. It is difficult, however, to make inferences on the effect of a single parameter such as speed (or orientation or dive time), which would allow a suitable hypothesis to be developed to implement such an alternative approach. Therefore, in the absence of a clear alternative approach, we chose to test only the null hypothesis of no impact whilst recognizing its limitations in this case with respect to detecting small or moderate effects if they were present.

We also highlight that individual responses were observed in conjunction with other factors such as direction of the sound source relative to the whale's position combined with increasing sound exposure levels. Such observations could contribute to understanding behavioural reactions to sound and/or vessel activity, but they were not considered explicitly in the analyses of this study. In addition, 'natural' factors that have been observed to influence gray whale behaviour in previous studies (Gailey et al. 2007b, 2010) were not found in this study to be significantly associated with behaviour variables; this could be a result of the limited sample sizes. Larger samples might have yielded a greater understanding of both the 'natural' (undisturbed) behaviour of the whales and the anthropogenic factors that may affect them.

Acknowledgements. We acknowledge Doug Bell, Judy Muir and Bernd Würsig for assisting in various phases of this study. We are grateful for the long hours and dedicated effort of the behavioural assistants Andrei Ermoshin, Alexei Filipiechev, Alexander Kalachev, Denis Kovshov, Ivan Krupin and Sarah Piwetz. Peter vanderWolf, Roman Larin and Igor Zhmaev provided excellent logistical assistance in the field. We also appreciate the valuable contributions of the Seismic Survey Task Force and the Western Gray Whale Advisory Panel (WGWAP) towards the development of the mitigation and monitoring measures employed during the seismic survey. IUCN has also been instrumental in providing a platform for scientists and industry to collaborate on issues surrounding the conservation of the western gray whale population. We thank the staff at LGL (Sidney, BC), JASCO Applied Sciences (Canada) and WEST for all their support throughout this project. We also thank the 4 anonymous reviewers for their suggestions and improvements of the manuscript. Finally, we thank Sakhalin Energy Investment Company for financial support.

\section{LITERATURE CITED}

Altmann J (1974) Observational study of behaviour: sampling methods. Behaviour 49:227-267

Baillie JEM, Hilton-Taylor C, Stuart SN (2004) 2004 IUCN Red List of Threatened Species: a global species assessment. IUCN, Gland

Beale CM (2007) The behavioral ecology of disturbance responses. J Comp Psychol 20:111-120 
Beale CM, Monaghan P (2004) Behavioural responses to human disturbance: a matter of choice? Anim Behav 68: 1065-1069

Bejder L, Samuels A, Whitehead H, Finn H, Allen S (2009) Impact assessment research: use and misuse of habituation, sensitisation and tolerance in describing wildlife responses to anthropogenic stimuli. Mar Ecol Prog Ser 395:177-185

Bogoslovskaya LS, Votrogov LM, Semenova TN (1981) Feeding habits of the gray whale off Chukotka. Rep Int Whal Comm 31:507-510

Borisov SV, Kovzel DG, Rutenk AN, Ushchipovskii VG (2008) A self-contained hydroacoustic station with radio channel for acoustic measurements on the shelf. Instrum Exp Tech 51:762-767

Bröker K, Gailey G, Muir J, Racca R (2015) Monitoring and impact mitigation during a $4 \mathrm{D}$ seismic survey near a population of gray whales off Sakhalin Island, Russia. Endang Species Res 28:187-208

Bryant PJ, Lafferty CM, Lafferty SK (1984) Reoccupation of Guerrero Negro, Baja California, Mexico, by gray whales. In: Jones ML, Swartz SL, Leatherwood, S (eds) The gray whale, Eschrichtius robustus. Academic Press, Orlando, FL, p 375-387

Cain ML (1989) The analysis of angular data in ecological field studies. Ecology(70):1540-1543

Clapham PJ, Baker CS (2002) Modern whaling. In: Perrin WF, Würsig B, Thewissen JGM (eds) Encyclopedia of marine mammals, 2nd edn. Academic Press, San Diego, CA, p 1328-1332

Cooke JG, Weller DW, Bradford AL, Sychenko O, Burdin AM, Brownell RL Jr (2013) Population assessment of Sakhalin gray whale aggregation. Paper SC/65a/BRG27 presented to the IWC Scientific Committee, Jeju, Korea. https:// swfsc.noaa.gov/publications/CR/2013/2013Cooke.pdf

> Dolphin WF (1987) Ventilation and dive patterns of humpback whales, Megaptera novaeangliae, on their Alaskan feeding grounds. Can J Zool 65:83-90

Dunlop RA, Noad MJ, Cato DH, Kniest E, Miller PJ, Smith JN, Stokes MD (2013) Multivariate analysis of behavioural response experiments in humpback whales (Megaptera novaeangliae). J Exp Biol 216:759-770

Ellison WT, Southall BL, Clark CW, Frankel AS (2012) A new context-based approach to assess marine mammal behavioral responses to anthropogenic sounds. Conserv Biol 26:21-28

Fadeev VI (2010) Benthos studies in feeding grounds of the Okhotsk-Korean gray whale population in 2009. Report to the Western Gray Whale Advisory Panel, Russian Academy of Sciences, Vladivostok

Gailey G, Ortega-Ortiz J (2002) A note on a computer-based system for theodolite tracking of cetaceans. J Cetacean Res Manag 4:213-218

Gailey G, Würsig B, McDonald T (2007a) Abundance, behavior, and movement patterns of western gray whales in relation to a 3-D seismic survey, northeast Sakhalin Island, Russia. Environ Monit Assess 134:75-91

Gailey G, McDonald T, Racca R, Sychenko O, Rutenko A, Würsig B (2007b) Influences of underwater sound and nearshore vessel activity on western gray whale behavior during the installation of a concrete gravity based structure off Sakhalin Island, summer 2005. Prepared for Exxon-Neftegas Ltd. and Sakhalin Energy Investment Company, Yuzhno-Sakhalinsk. http://cmsdata.iucn.org/ downloads/wgwap_2_inf_7__mva.pdf
Gailey G, McDonald T, Racca R, Sychenko O and others (2010) Western gray whale movement, respiration, and abundance during pipeline construction off Sakhalin Island, Russia. Prepared for Exxon-Neftegas Ltd. and Sakhalin Energy Investment Company, Yuzhno-Sakhalinsk

Guerrero JA (1989) Feeding behavior of gray whales in relation to patch dynamics of their benthic prey. MSc thesis, San Jose State University, San Jose, CA

Hawkinson CA (1992) Feeding ecology of gray whales in Agate Bay, California, summers 1990 and 1991. MSc thesis, San Jose State University, San Jose, CA

> Horvitz DG, Thompson DJ (1952) A generalization of sampling without replacement from a finite universe. J Am Stat Assoc 47:663-685

IWC (International Whaling Commission) (2015) Report of the workshop on the rangewide review of the population structure and status of North Pacific gray whales. J Cetacean Res Manag 16(suppl):489-528

Jahoda MC, Lafortuna C, Biasson N, Almirante C and others (2003) Mediterranean fin whale's (Balaenoptera physalus) response to small vessels and biopsy sampling assessed through passive tracking and timing of respiration. Mar Mamm Sci 19:96-110

Johnson SR, Richardson WJ, Yazvenko SB, Blokhin SA and others (2007) A western gray whale mitigation and monitoring program for a 3-D seismic survey, Sakhalin Island, Russia. Environ Monit Assess 134:1-19

Jones ML, Swartz SL (2009) Gray whale Eschrichtius robustus. In: Perrin WF, Würsig B, Thewissen JGM (eds) Encyclopedia of marine mammals, $2^{\text {nd }}$ edn. Academic Press, San Diego, CA, p 503-511

Kovzel DG, Rutenko AN (2009) A self-contained acoustic station with a digital radiotelemetry channel for monitoring seismic acoustic signals on the shelf. Instrum Exp Tech 52:857-861

Laake JL, Punt AE, Hobbs R, Ferguson M, Rugh D, Breiwick J (2012) Gray whale southbound migration surveys $1967-$ 2006: an integrated re-analysis. J Cetacean Res Manag 12:287-306

Ljungblad DK, Würsig B, Swartz SL, Keene JM (1988) Observations of the behavioral responses of bowhead whales (Balaena mysticetus) to active geophysical vessels in the Alaskan Beaufort Sea. Arctic 41:183-194

Mallonee JS (1991) Behaviour of gray whales (Eschrichtius robustus) summering off the northern California coast, from Patrick's Point to Crescent City. Can J Zool 69: 681-690

Malme CI, Würsig B, Bird JE, Tyack P (1986) Behavioral responses of gray whales to industrial noise: feeding observations and predictive modeling. Outer Continental Shelf Environmental Assessment Program, final report of principal investigators. NOAA No. PB-88-249057/ XAB. BBN Labs, Cambridge, MA

Malme CI, Würsig B, Bird JE, Tyack P (1988) Observations of feeding gray whale responses to controlled industrial noise exposure. In: Sackinger WM, Jefferies MO, Imm JL, Treacy SD (eds) Port and ocean engineering under Arctic conditions, Vol 2. University of Alaska, Fairbanks, $\mathrm{AK}, \mathrm{p}$ 55-73

Martin B, Bateson P (1993) Measuring behaviour: an introductory guide, 2nd edn. Cambridge University Press, Cambridge

Nowacek DP, Thorne LH, Johnston DW, Tyack PL (2007) Responses of cetaceans to anthropogenic noise. Mammal Rev 37:81-115 
Nowacek DP, Bröker K, Donovan G, Gailey G and others (2013) Responsible practices for minimizing and monitoring environmental impacts of marine seismic surveys with an emphasis on marine mammals. Aquat Mamm 39: 356-377

Overton WS, Stehman SV (1995) The Horvitz-Thompson theorem as a unifying perspective for probability sampling: with examples from natural resource sampling. Am Stat 49:261-268

Pinheiro JC, Bates DM (2000) Mixed-e ects models in S and S-PLUS. Springer-Verlag, New York, NY

Punt AE, Wade PR (2012) Population status of the eastern North Pacific stock of gray whales in 2009. J Cetacean Res Manag 12:15-28

R Development Core Team (2010) R: a language and environment for statistical computing. R Foundation for Statistical Computing, Vienna

Racca R, Austin M, Rutenko A, Bröker K (2015) Monitoring the western gray whale sound exposure zone and estimating acoustic transmission during a 4-D seismic survey, Sakhalin Island, Russia. Endang Species Res 29: 131-146

Red Book of the Russian Federation (2000) Red data book of the Russian Federation: animals. AST \& Astrel Publishers, Moscow

Richardson WJ, Malme CI (1993) Man-made noise and behavioral responses. In: Burns JJ, Montague JJ, Cowles CJ (eds) The bowhead whale. Society for Marine Mammalogy Spec Publ 2:631-700

Richardson WJ, Würsig B (1995) Significance of responses and noise impacts. In: Richardson WJ, Greene CR, Thomson DH (eds) Marine mammals and noise. Academic Press, San Diego, CA, p 387-424

Richardson WJ, Fraker MA, Würsig B, Wells RS (1985) Behaviour of bowhead whales Balaena mysticetus summering in the Beaufort Sea: reactions to industrial activities. Biol Conserv 32:195-230

Richardson WJ, Würsig B, Greene CR Jr (1986) Reactions of bowhead whales, Balaena mysticetus, to seismic exploration in the Canadian Beaufort Sea. J Acoust Soc Am 79: 1117-1128

Robertson FC, Koski WR, Thomas TA, Richardson WJ, Würsig B, Trites AW (2013) Seismic operations have variable effects on dive-cycle behavior of bowhead whales in the Beaufort Sea. Endang Species Res 21:143-160

Rugh DJ, Hobbs RC, Lerczak JA, Breiwick JM (2005) Estimates of abundance of the eastern North Pacific stock of gray whales (Eschrichtius robustus) 1997-2002. J Cetacean Res Manag 7:1-12

Rutenko AN, Borovoi DI, Gritsenko VA, Petrov PS, Ushchipovskii VG, Boekholt M (2012) Monitoring the acoustic field of seismic survey pulses in the near-coastal zone. Acoust Phys 58:326-338

SEIC (Sakhalin Energy Investment Company) (2005) Marine mammal protection plan: a framework for mitigation and monitoring related to Sakhalin Energy oil and gas operations, Sakhalin Island, Russia. Sakhalin Energy Investment Company, Yuzhno-Sakhalinsk http://cmsdata.iucn. org/downloads/wgwap_7_doc_24_marine_mammal_ protection_plan.pdf

SEIC (Sakhalin Energy Investment Company) (2006) Marine mammal protection plan: a framework for mitigation and monitoring related to Sakhalin Energy oil and gas operations, Sakhalin Island, Russia. Sakhalin Energy Investment Company, Yuzhno-Sakhalinsk

SEIC (2007) (Sakhalin Energy Investment Company) Marine mammal protection plan: a framework for mitigation and monitoring related to Sakhalin Energy oil and gas operations, Sakhalin Island, Russia. Sakhalin Energy Investment Company, Yuzhno-Sakhalinsk. www.sakhalin energy.com/en/documents/Marine_Mammal_Protection Plan_eng.pdf

Southall BL, Bowles AE, Ellison WT, Finneran JJ and others (2007) Marine mammal noise exposure criteria: initial scientific recommendations. Aquat Mamm 33:411-522

SSTF (Seismic Survey Task Force) (2007-2011) Seismic Survey Task Force reports 1-7 to the Western Gray Whale Advisory Panel. http://iucn.org/wgwap/wgwap/ task_forces/seismic_survey_task_force/

Stelle LL, Megill WM, Kinzel MR (2008) Activity budget and diving behavior of gray whales (Eschrichtius robustus) in feeding grounds off coastal British Columbia. Mar Mamm Sci 24:462-478

Swartz SL, Jones ML (1979) The evaluation of human activities on gray whales, Eschrichtius robustus, in Laguna San Ignacio, Baja California, Mexico. Final report to US Marine Mammal Commission, Bethesda, MD

Turchin P (1998) Quantitative analysis of movement. Sinauer Associates, Sunderland, MA

Tyack PL, Clark CW (1998) Playback of low-frequency sound to gray whales migrating past the central California coast - January, 1998. Quick look report phase II: playbacks to migrating gray whales. Woods Hole Oceanographic Institution, Woods Hole, MA

Weller DW, Würsig B, Bradford AL, Burdin AM and others (1999) Gray whales (Eschrichtius robustus) off Sakhalin Island, Russia: seasonal and annual occurrence patterns. Mar Mamm Sci 15:1208-1227

Weller DW, Ivashchenko YV, Tsidulko GA, Burdin AM, Brownell RL Jr (2002) Influence of seismic surveys on western gray whales off Sakhalin Island, Russia in 2001. Paper SC/54/BRG14 presented to the IWC Scientific Committee, Shimonoseki. http://digitalcommons.unl. edu/cgi/viewcontent.cgi? article=1064\&context=usdept commercepub

Weller DW, Rickards SH, Bradford AM, Burdin AM, Brownell RL Jr (2005) The influence of 1997 seismic surveys on the behaviour of western gray whales off Sakhalin Island, Russia. Paper SC/58/E4 presented to the IWC Scientific Committee, Cambridge

> Würsig B, Wells RS, Croll DA (1986) Behavior of gray whales summering near St. Lawrence Island, Bering Sea. Can J Zool 64:611-621

Würsig B, Cipriano F, Würsig M (1991) Dolphin movement patterns: information from radio and theodolite tracking studies. In: Pryor K, Norris KS (eds) Dolphin societies: discoveries and puzzles. University of California Press, Los Angeles, CA p 79-112

Würsig B, Gailey G, McDonald T, Nielson R and others (2002) Western gray whale occurrence patterns and behavior: shore-based observations off Sakhalin Island, August-September 2001. Prepared for Exxon-Neftegas Ltd. and Sakhalin Energy Investment Company, YuzhnoSakhalinsk

Yazvenko SB, McDonald TL, Blokhin SA, Johnson SR and others (2007a) Distribution of western gray whales during a seismic survey near Sakhalin Island, Russia. Environ Monit Assess 134:45-73

Yazvenko SB, McDonald TL, Blokhin SA, Johnson SR and others (2007b) Feeding of western gray whales during a seismic survey near Sakhalin Island, Russia. Environ Monit Assess 134:93-106 